\title{
Colloidal gas aphrons separation to obtain polyphenol rich fractions from artichoke agro-industrial discards
}

Article

Accepted Version

Creative Commons: Attribution-Noncommercial-No Derivative Works 4.0

Noriega, D., Zuñiga, M. E., Soto, C., MohdMaidin, N., Michael, N. and Jauregi, P. (2018) Colloidal gas aphrons separation to obtain polyphenol rich fractions from artichoke agro-industrial discards. Food and Bioproducts Processing, 110. pp. 50-59. ISSN 0960-3085 doi: https://doi.org/10.1016/j.fbp.2018.04.007 Available at https://centaur.reading.ac.uk/77185/

It is advisable to refer to the publisher's version if you intend to cite from the work. See Guidance on citing.

To link to this article DOI: http://dx.doi.org/10.1016/j.fbp.2018.04.007

Publisher: Elsevier

All outputs in CentAUR are protected by Intellectual Property Rights law, including copyright law. Copyright and IPR is retained by the creators or other copyright holders. Terms and conditions for use of this material are defined in the End User Agreement.

www.reading.ac.uk/centaur 
Central Archive at the University of Reading

Reading's research outputs online 


\title{
Colloidal Gas Aphrons Separation to Obtain Polyphenol Rich Fractions from Artichoke Agro-industrial Discards
}

\author{
Diana Noriega ${ }^{\mathrm{a}, \mathrm{b}}$, Maria Elvira Zuñiga $^{\mathrm{c}}$, Carmen Soto $^{\mathrm{d}}$, Nurmahani MohdMaidine, Nicholas \\ Michael $^{f}$, and Paula Jauregi ${ }^{2 *}$ \\ a Department of Food and Nutritional Sciences, The University of Reading, Reading, United \\ Kingdom \\ ${ }^{\mathrm{b}}$ Marine Science, Technology \& Management, Campus do Mar, Universidad de Vigo, Spain \\ c Pontificia Universidad Catolica de Valparaiso, Av Brasil 2085, Valparaiso, Chile \\ dCentro Regional de Estudios en Alimentos Saludables (CREAS), R12C1001, Avenida \\ Universidad 330, Curauma, Valparaíso, Chile \\ e Department of Food Technology, Faculty of Food Science and Technology, Universiti Malaysia \\ Terengganu, Malaysia \\ ${ }^{f}$ Chemical Analysis Facility (CAF), Department of Chemistry, Harborne Building, The University \\ of Reading, Reading, United Kingdom \\ *corresponding author at: Department of Food and Nutritional Sciences, Harry Nursten, \\ University of Reading, PO Box 226, Whiteknights, Reading, RG6 6AP, United Kingdom \\ Tel: +44 (0) $1183788728 \quad$ Fax: 01189310080
}

\begin{abstract}
Artichoke agro-industrial discards have proved an excellent source of polyphenolic compounds with high antioxidant capacity, which can be extracted at mild conditions. The aim of this study was to further separate these bioactive molecules from an ethanolic extract by using Colloidal Gas Aphrons (CGAs) generated from a cationic surfactant, Cetyl trimethylammonium bromide, CTAB $(1 \mathrm{mM})$ and a nonionic one, Tween $20(10 \mathrm{mM})$. Total proteins, total sugars, total phenolic content (TPC), antioxidant capacity (AOC) and polyphenolic profile were determined in the crude extracts and CGA fractions. Highest recovery was obtained with the nonionic Tween 20 at CGA to feed volumetric ratio $5(\mathrm{RE} \%=64)$ whereas the cationic $C T A B$ proved more efficient $(\mathrm{RE} \%=58)$ at the highest ratio studied here (ratio 11). Antioxidant capacity followed the same trend as the recovery of polyphenols and highest enrichment in antioxidant activity for each of the
\end{abstract}


surfactants (1.5 for Tween 20 and 1.4 for CTAB) was obtained at those conditions that led to maximum recovery. Highest selectivity was obtained with CTAB. The interactions between the negatively charged polyphenols and the positively charged cationic surfactant drove the separation, whereas with Tween 20 hydrophobic interactions were predominant, and at the studied concentrations $(10 \mathrm{mM})$ the separation of polyphenols within the micelles might also compete with the CGA separation. Polyphenolic profile of feed and CGAs fractions comprised mainly mono and dicaffeoylquinic acids and a small proportion of flavones. In most of the cases no enrichment of any particular polyphenol compound was observed from the initial extract to CGAs samples generated with Tween 20 and CTAB. However, at ratio 5 and with Tween, CGAs were enriched in dicaffeoylquinic acid. Future research should focus on studying further the activities and stability of these surfactant rich fractions in order to assess if the surfactant could offer any advantage to the formulation of these polyphenols.

Keywords: artichoke by-products, colloidal gas aphrons, bioseparation, polyphenols, antioxidant capacity

\section{INTRODUCTION}

Globe artichoke (Cynara scolymus) is a herbaceous perennial plant belonging to the Astaracea family. It is worldwide cultivated and considered one of the greatest sources of antioxidants in the vegetal kingdom (Jiménez-Escrig et al., 2003; Ceccarelli et al., 2010; Ruiz-Cano et al., 2014) as well as presenting a great hypocholesterolemic (Lattanzio et al., 2009; Da Costa et al., 2009; Bekheet, 2011), anticarcinogenic (Shukla \& Gupta, 2010; Pereira et al., 2013), antidyspeptic (Marakis et al., 2002), antiseptic and antibiotic activities (Zhu et al., 2004; Gaafar and Salama, 2013; Fratianni et al., 2014) among others. This vegetable is consumed fresh but mainly in its canned form. The edible portion of the plant is around a 15\% of its total weight (Lattanzio et al., 2009; Negro et al., 2012; Pandino et al, 2013), so the discards and by-products associated to its consumption are substantial and their management at large scale may pose environmental and 
economical costs (Llorach et al., 2002). This creates an excellent opportunity to the valorisation of these so-called discards in order to obtain a product with health-promoting activity (Llorach et al., 2002; Schutz et al., 2006; Lattanzio et al., 2009; Ceccarelli et al., 2010; Garbetta et al., 2014 , Galanakis, 2013), to be used in a number of sectors; food, nutraceutical, medical and pharmaceutical and cosmetic industries, among others.

The extraction of polyphenolic compounds from artichoke, and most vegetables, is accomplished by the use of a wide range of solvents, mostly aggressive ones which limit the application of the resultant extracts for human consumption (Wang et al., 2003; Pandino et al., 2010; Negro et al., 2012; Fratianni et al., 2014). In this aspect, ethanolic solutions, which due to their innocuousness do not necessarily have to be removed, have been reported to be the most efficient in the extraction of polyphenols in terms of TPC and AOC displayed (Zuorro et al., 2014; Soto et al., 2014). However, the environmental and economical input of these techniques at the industry level, is considerable. In this scenario an opportunity arises to use innovative extraction techniques. Some of the emerging extraction techniques include Colloidal Gas Aphrons (CGA) (Galanakis, 2012). The use of CGA at this stage can be advantageous as it will avoid the use of large volumes of alcoholic solvents and can lead to the recovery of polyphenols in a surfactant rich solution which could be advantageous for their formulation (MohdMaidin et al, 2017).

CGAs are microbubbles encapsulated by surfactant multilayers; microfoams with colloidal properties (Sebba, 1987; Jauregi and Varley, 1999) with increased interface area to adsorb charged and/or hydrophobic molecules, resulting in the recovery of biological molecules (Jauregi and Dermiki, 2010). CGAs consist of a gaseous inner core surrounded by a thin double aqueous surfactant film and a third surfactant layer which stabilizes the structure. Depending on the anionic, cationic or non-ionic nature of the surfactant, the outer layer of the microbubbles produced will be charged or non-charged. If charged, they will attract oppositely charged molecules/particles resulting in their subsequent removal from the solution; similarly, noncharged molecules/particles will interact with the non-charged outer layer of the microbubbles 
mainly by hydrophobic interactions. Type and concentration of the surfactant determine the size of the bubbles formed and their availability to interact with the particles (Mansur et al., 2006; Jauregi and Dermiki, 2010). CGAs separate easily from the bulk liquid (liquid phase) because of their buoyancy without using mechanical aids (as opposed to liquid-liquid extraction methods) and therefore is a feasible application on separation procedures with high recoveries and low costs due to low energy requirements (Jauregi and Varley, 1999; Spigno et al., 2015; Dermiki et al., 2009). Furthermore, the use of food grade surfactants, as non-ionic ones leads to a more simplified process as there is no need for their removal (Dermiki et al., 2009; Jauregi and Dermiki, 2010; Spigno et al., 2010). So far, CGAs have been used in the removal of metals, dyes (Huang et al., 2003) and toxic compounds (Mansur et al., 2006; Mukhopadhyay et al., 2015) from wastewaters and other effluents, amongst other applications (Molaei and Waters, 2015). Moreover, CGAs have been applied to the recovery of bioactive molecules such as enzymes (Jauregi and Varley, 1999; Noble and Varley, 1999), yeast cells (Hashim et al., 2000), proteins (Fuda et al., 2004 \& 2005), carotenoids (Dermiki et al, 2009; Alves et al., 2006) and antioxidants (Spigno and Jauregi, 2005; Dermiki et al., 2009; Spigno et al., 2010 Spigno et al., 2011; MohdMaidin et al., 2017). The use of some surfactants, such as Tween, has shown protection of polyphenolic compounds from oxidation (Lin et al., 2007; Spigno et al., 2014) and enhancement in the efficiency of the delivery of polyphenols in skin formulations (Yutani et al., 2012). Moreover, there could be an advantage in the formulation and encapsulation of polyphenolic concentrates, as a recent research has shown the synergistic stability effect observed between CGAs and nanoparticles (Amiri and Sadeghialiabadi, 2015) and the potential opening up to their use with more novel natural encapsulating materials different from those found nowadays in the market.

The main purpose of this study is to gain an insight in the suitability and feasibility of separation by CGAs of polyphenolic compounds from an artichoke discards hydroalcoholic extract, which, to the best of our knowledge, has not been assessed yet. The separation performance of CGAs 
produced by a cationic and a non-ionic surfactant was compared based on the recovery of total and individual polyphenols, selectivity of the separation in relation to protein and sugar content and antioxidant activity displayed.

\section{MATERIALS AND REAGENTS}

The raw matter is composed of artichoke discards (outer bracts and stems) from a processing factory in San Felipe (Chile), freeze-dried and grinded. The starting feed for the CGAs procedure is a hydroalcoholic extract of the aforementioned by-products obtained with a 60:40 ethanol:water solution, $1: 15$ sample:volume $(\mathrm{g}: \mathrm{mL})$ ratio, $40^{\circ} \mathrm{C}$ of temperature and 10 minutes of extraction time at a linear agitation of $100 \mathrm{rpm}$.

Tween 20 (Polyethylene glycol sorbitan monolaurate) and CTAB (Cetyl trimethyl ammonium bromide) were purchased from Fluka-Sigma-Aldrich, (Germany).

Folin-Ciocalteu phenol reagent, $\mathrm{NaCO}_{3}, \mathrm{NaOH}$, were purchased from Merck (USA); 2,2-azobis (2 methyl propionamidine) dihydrochloride (AAPH), phosphate buffered tablets, 3,4,5-trihydroxy benzoic acid (Gallic acid), 6-hydroxy-2,5,7,8-tetramethylchroman-2-carboxylic acid (Trolox) were purchased from Sigma-Aldrich (Germany).

Acetonitrile and formic acid HPLC grade were from Sigma Aldrich (Germany). Ethanol and other analytical grade solvents were purchased from Merck (USA).

HPLC and MS-LC standards: 5-O-caffeoylquinic acid (chlorogenic acid), 1, 3-O- dicaffeoylquinic acid (cynarin) and the flavones: luteolin, apigenin and apigenin -7-0-glucosyde, all >95\% purity, were purchased from Sigma Aldrich (Germany). 


\subsection{METHODOLOGY}

\subsubsection{Characterization of Initial Ethanolic Extracts and CGAs Samples}

Two initial hydroalcoholic extracts (feeds) were produced - due to volume restrictions in the available laboratory equipment - at the conditions stated above. Feed A was used for volumetric ratio 2:1 CGAs:Feed tests and Feed $\mathrm{B}$ for volumetric ratios 5:1 and 11:1 CGAs:Feed ones. All parameters studied on CGAs and liquid phases samples were conducted by duplicate in pairs with regard to their corresponding initial extract on same day of preparation. The extracts were prepared on the same day or two days before the CGA separation in order to avoid losses of antioxidant activity and stored at $-18^{\circ} \mathrm{C}$ when appropriate; in a separate study we found that the losses in refrigerated samples was minimal.

Both feeds and final samples were characterized in regard to their protein and sugar content. Total proteins were determined with BCA Protein Assay (Sigma-Aldrich, Germany) and the results expressed as milligrams of BSA Equivalents per liter; mg BSA E/L, and milligrams of BSA Equivalents per 100 grams (dry weight); mg BSA E/100 g (dw).

Total sugars were determined using Dubois procedure (Dubois et al., 1956) and results are expressed as milligrams of Glucose Equivalents per litre ( $\mathrm{mg} \mathrm{Glc} \mathrm{E} / \mathrm{L}$ ) and milligrams of Glucose Equivalents per 100 grams (dry weight); mg Glc E/100 g (dw).

pH was also assessed with a M900-Series $\mathrm{pH}$-meter (Maan) for the ethanolic extracts and samples. Neither buffers nor reagents were used to adjust $\mathrm{pH}$ values.

\subsubsection{Determination of Total Phenolic Content (TPC)}

The total polyphenol content (TPC) was determined according to Soto et al. (2014); $0.5 \mathrm{~mL}$ sample added to a test tube containing $3.75 \mathrm{~mL}$ of distilled water. Feeds were previously diluted 1:50 \& 1:20 in ethanol $60 \%$ and CGAs samples $1: 10$ in distilled water. $0.25 \mathrm{~mL}$ of the FolinCiocalteau reagent $50 \%$ and $0.5 \mathrm{~mL}$ of sodium carbonate $10 \%$ concentrated were then added to the test tube and shaken. Samples were allowed to stand at room temperature for 1-2 hours 
until final reading at $765 \mathrm{~nm}$ wavelength. The resultant absorbances were interpolated with a calibration curve of gallic acid (in a concentration range of 0-0.2 g/L). Results were expressed as milligrams of Gallic Acid Equivalents per litre; g GA E/L, and milligrams of Gallic Acid Equivalents per 100 grams (dry weight); mg GA E/ $100 \mathrm{~g}(\mathrm{dw})$.

\subsubsection{Determination of the Antioxidant Capacity (AOC)}

The antioxidant capacity (AOC) was determined by ABTS; 2, 2'-Azino-bis (3-ethylbenzothiazoline -6 - sulfonic acid) technique proposed by Pellegrini et al. (1999) with subtle adaptations; $5 \mathrm{~mL}$ of $7 \mathrm{mM}$ ABTS solution was mixed with $88 \mu \mathrm{L}$ of $140 \mathrm{mM}$ potassium persulfate $\left(\mathrm{K}_{2} \mathrm{~S}_{2} \mathrm{O}_{8}\right)$ and allowed to sit for at least 16 hours in the dark, at room temperature. The working solution consisted of the mix diluted in ethanol until an absorbance of $0.700+/-0.020$ was reached at a wavelength of $734 \mathrm{~nm} .2 \mathrm{~mL}$ of this working reagent was added to $20 \mu \mathrm{L}$ of each sample and initial feed, homogenated and read in spectrophotometer at $734 \mathrm{~nm}$ after 6 minutes in the dark. A Trolox calibration curve (Trolox concentration ranged from 0 to $200 \mu \mathrm{M}$ ) was plotted to determine the $A O C$, expressed as the inhibition of $A B T S$ radical activity. Results are expressed as $\mu \mathrm{mol}$ Trolox Equivalents per liter; $\mu \mathrm{mol} \mathrm{T} \mathrm{E} / \mathrm{L}$, and $\mu \mathrm{mol}$ Trolox Equivalents per 100 grams (dried weight); $\mu \mathrm{mol} \mathrm{T} \mathrm{E} / 100 \mathrm{~g}(\mathrm{dw})$.

\subsubsection{Generation of CGAs and separation}

Same procedure reported by other authors in the group (Spigno et al., 2010; 2014) was followed: surfactants Tween $2010 \mathrm{mM}$ and CTAB $1 \mathrm{mM}$, were stirred in a high speed homogenizer by Silverson at $8000 \mathrm{rpm}$ for 5 minutes to obtain the microbubbles $(10-100 \mu \mathrm{m})$, which were immediately transferred by peristaltic pump (Watson Marlow $505 \mathrm{U}$ ) into a glass flotation column where the corresponding volume of hydroalcoholic extract had been placed.

\subsubsection{CGAs Characterization and Stability Tests}

Stability was assessed by measuring the drainage rate; volume of CGAs drained back into liquid until a plateau is reached, gas hold up ( $(\varepsilon)$; defined as the volumetric fraction of air in the aphrons 
and half-life (T); time taken for half of the original liquid to drain. The stability of the CGAs will also depend on the concentration of surfactant used. Maximum stability when the concentration of surfactant is above the critical micellar concentration (CMC); concentration above which micellar formation becomes appreciable, as this case (CTAB CMC: $0.8-1 \mathrm{mM}$; Tween $20 \mathrm{CMC}: 0.003 \mathrm{mM})$. The three tests were conducted in triplicate both with Tween $20(10 \mathrm{mM})$ and CTAB (1mM) following same procedure reported by Spigno et al. (2014).

\subsubsection{CGAs Separation Procedure}

A glass flotation column with a total volume of $720 \mathrm{~mL}$ was used for the separation process operated in batch mode. The tested volumetric ratios CGAs:Feed were: 2:1, 5:1 and 11:1 - from now on 2, 5 and 11 . These were obtained by mixing the following CGAs $(\mathrm{mL})$ and Feed $(\mathrm{mL})$ volumes: 480:240; 600:120 and 660:60 for 2, 5 and 11 ratios respectively. Flow rate was adjusted to meet the fixed criteria for the separation: contact time, defined as time taken for the CGAs to enter the column to the final desired volume, and drainage time; time allowed for the interaction of CGAs with the feed once stirring had finished and the subsequent separation of the liquid and CGAs phases started to take place. Both contact and drainage times were set at 5 minutes for all tests performed with Tween $20(10 \mathrm{mM})$ and CTAB $(1 \mathrm{mM})$. The aphrons which separated into liquid (LP) and CGAs phases were both recovered, measured and analysed. All tests were conducted in duplicate in pairs with the same initial extract on day of preparation. The efficiency of the separation process for total phenols, total proteins and total sugars for both Tween 20 and CTAB was evaluated by the following parameters:

1.-Recovery (Re \%): Mass of a specific compound in the CGAs phase in relation to the compound mass in the initial feed.

$\operatorname{Re}(\%)=\left(\right.$ Mass $^{*}$ compound CGAs $/$ Mass compound Feed $) \times 100$ 
* Mass of compound in CGA phase was measured based on measurement in the liquid phase and by applying a mass balance. Direct measure of the CGAs mass was also made, with a deviation of $0-3 \%$ to the mass balance calculation.

2.-Separation Ratio (SR): Concentration of a compound recovered in the CGAs phase in relation to the counterpart liquid phase (LP)

SR = Concentration compound ${ }_{\mathrm{CGAS}} /$ Concentration compound $\mathrm{LP}_{\mathrm{P}}$

\subsubsection{Determination of Polyphenolic Profile}

The determination of polyphenolic compounds present in initial extracts and samples was conducted with HPLC equipment (Agilent, Z220 HDm3) with DAD and UV detectors by the method proposed by Pandino et al. (2013) with subtle adaptations; the stationary phase was a Zorbax Eclipse XDB-C18 column (4.6 mm x $150 \mathrm{~mm}, 5 \mu \mathrm{m}$ particle size). Mobile phases were A: Water with $1 \%$ formic acid, and B: Acetonitrile with $1 \%$ formic acid. A flow rate of $1 \mathrm{~mL} / \mathrm{min}$ was maintained throughout the gradient: $5 \%$ B for $5 \min , 10 \%$ B for $10 \mathrm{~min}, 40 \%$ B for $15 \mathrm{~min}, 90 \%$ B for $5 \mathrm{~min}$ and back to $5 \% \mathrm{~B}$ for a further $5 \mathrm{~min}$. The injection volume was $100 \mu \mathrm{L}$ for extract samples and $20 \mu \mathrm{L}$ for control standards; Apigenine-7-glucoside, Apigenin, Chlorogenic acid, Cynarin and Luteolin. The reading wavelengths were 280, 320 and $365 \mathrm{~nm}$. Chromatogram results obtained at $320 \mathrm{~nm}$ readings proved more suitable in terms of peak definition and resolution therefore it was decided to show final results of the polyphenolic profile based on chromatograms obtained at this wavelength.

LC-MS analysis was performed to add confidence to the identification of key polyphenols found by the initial HPLC analysis. These were performed on an Accela HPLC system interfaced to an LTQ Orbitrap XL (Thermo Scientific). In brief standards (diluted to $10 \mu \mathrm{g} / \mathrm{mL}$ in LCMS grade water from $100 \mu \mathrm{g} / \mathrm{mL}$ stocks that had been dissolved in $60 \%$ ethanol) of Apigenine-7-glucoside, Apigenin, Chlorogenic acid, Cynarin and Luteolin were run on the same column as was used for the HPLC analysis. The buffers were A: Water with $0.1 \%$ formic acid and B: Acetonitrile with $0.1 \%$ formic acid (all Sigma Aldrich LCMS grade) at a flow rate of $0.8 \mathrm{~mL} / \mathrm{min}$ 
throughout the gradient: 5\% B for $5 \mathrm{~min}, 15 \%$ B for $10 \mathrm{~min}, 30 \%$ B for $15 \mathrm{~min}, 50 \%$ B for $10 \mathrm{~min}$, up to $95 \%$ B over 5 min and back to $5 \%$ B over $5 \mathrm{~min}$ and held for $10 \mathrm{~min}$. The injection volume was $20 \mu \mathrm{L}$ for all injections. The reading wavelength was $320 \mathrm{~nm}$. After the UV cell the flow was put through a splitter with approximately $25 \%$ being directed into the MS. The MS was operating in negative ion mode and performing a data-dependent analysis (DDA) during which an MS scan event was performed at a resolution of 30,000 in the Orbitrap detector. Prominent ions from this scan were isolated and fragmented (MS/MS) and scanned out in the LTQ ion trap detector at unit resolution. Extracted ion chromatograms were generated in each standard and sample for each compound based upon the predicted negative ion $\mathrm{m} / \mathrm{z}$ with accuracy tolerances of $<5 \mathrm{ppm}$.

Relative retention times of peaks in the standards and samples confirmed by the LC-MS analysis were compared to the HPLC ones in order to identify peaks that were found in the HPLC analysis.

\subsubsection{Statistics}

The results were statistically analysed by analysis of variance using $\mathrm{IBM}^{\circ} \mathrm{SPSS}^{\circ}$ Statistics version 24.0. One-way ANOVA was performed to test the significance of changes in polyphenol composition with the ratio (Note: the feed was considered ratio 0 ) and the multiple comparisons test was carried out by the Bonferroni test. Comparison of the two feeds ( $\mathrm{A}$ and $\mathrm{B}$ ) was carried out by the independent t-test.

\section{RESULTS AND DISCUSSION}

\subsection{CGAs Stability Tests}

Figure 1 shows the drainage rate of the CGAs phases in surfactants Tween $20(10 \mathrm{mM})$ and CTAB $(1 \mathrm{mM})$, which indicates a similar stability and performance of CGAs created with both surfactants. These concentrations of the surfactants were reported the most efficient in previous studies (Dermiki et al., 2009; Spigno et al., 2011). Half-life (T) values were 510 seconds 
for Tween 20 and 444 seconds for CTAB. On the other hand, gas hold up (E) were $57 \%$ and $49 \%$ for Tween 20 and CTAB respectively.

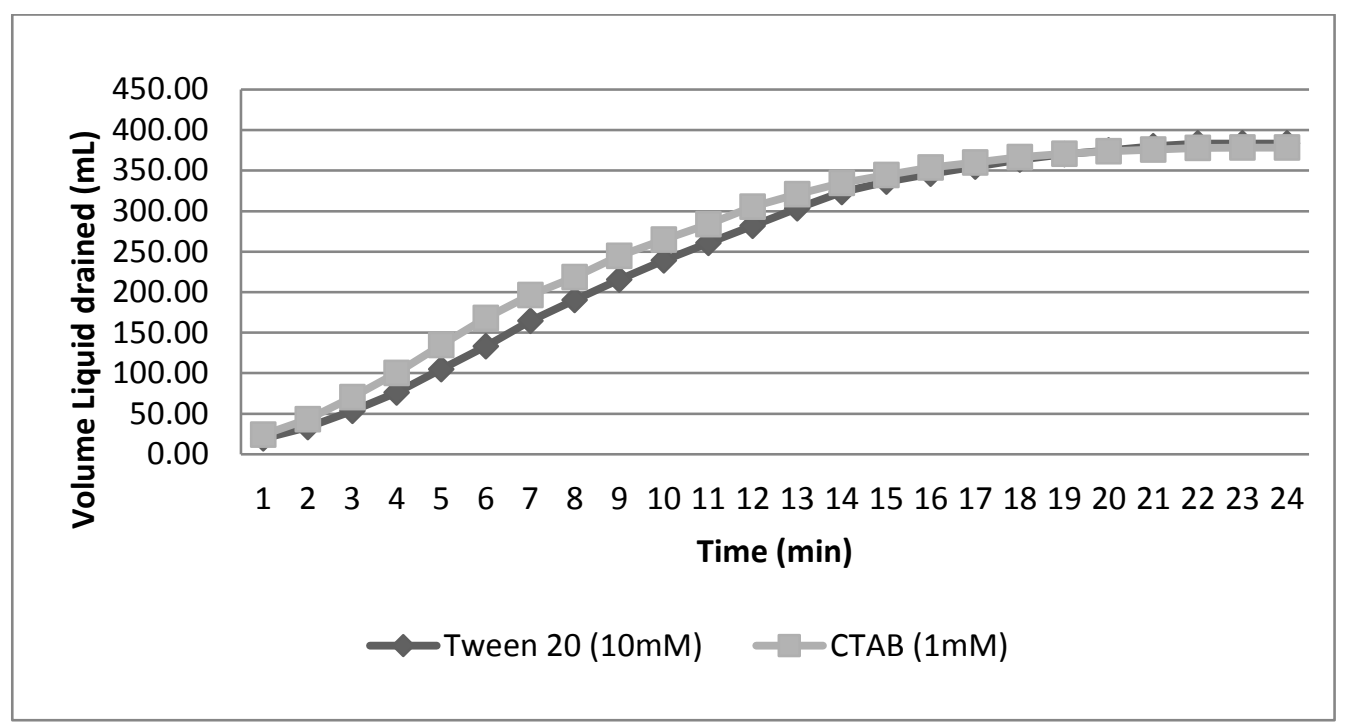

Figure 1. Drainage rate for Tween $20(10 \mathrm{mM})$ and CTAB $(1 \mathrm{mM})$ CGAs.

In the light of these results, Tween 20 CGAs present slightly more stability than CTAB CGAs,. but the concentration of Tween was ten times higher than that of CTAB.

Molar concentrations of the surfactants in our study are above their $\mathrm{CMC} ; \mathrm{CMC}(\mathrm{CTAB})=0.9 \mathrm{mM}$ and $C M C($ Tween20) $=0.08 \mathrm{mM}$. At these concentrations, the stability of CGAs increases because under these conditions a viscous liquid-crystalline phase is formed in the bulk liquid and the drainage of the foam is delayed (Dermiki et al., 2009). In the case of the cationic surfactant CTAB the repulsive electrostatic interactions between CGA bubbles will hinder their coalescence resulting in higher stability dispersions (Spigno et al., 2010; Fuda et al., 2004). In any case, higher concentrations of neutral surfactants are needed to produce stable CGAs than for ionic ones, although the former have a lower $\mathrm{CMC}$, likely because of the non-charged and larger surface area of non-ionic CGAs (Sebba et al., 1987; Dermiki et al., 2009; Spigno et al., 2014). However, it must be noted that higher concentration of surfactant, inhibits the diffusion of gas between the bubbles, and then no further increase in stability occurs (Dermiki et al., 2009; Fuda et al., 2004). 
Higher gas hold-up was obtained for Tween than for CTAB. Since gas hold-up determines the available interfacial area of the CGAs, it will therefore influence the recovery of the compounds (Spigno et al, 2014; Dermiki et al, 2009).

\subsection{Chemical characterization of the initial hydroalcoholic extract}

Table 1 shows the chemical characterization of the initial extracts; Feed A: used for ratio 2 tests and feed $B$ used for tests on ratios 5 and 11 , in terms of phenolic content, total proteins, total sugars and antioxidant capacity (AOC).

Table 1. Total phenolic content (TPC), Total proteins, Total Sugars and Antioxidant Capacity (AOC) of initial hydroalcoholic extracts (+/- Standard Deviation).

TPC

Total Proteins

Total Sugars

AOC

mg GA E/100 g (dw) mg BSA E/100 g (dw) mg Glc E/100 g (dw) $\mu \mathrm{mol}$ T E/100 g (dw)

\begin{tabular}{c|c|c|c|c}
$\begin{array}{l}\text { Feed A } \\
\text { Ratio 2 }\end{array}$ & $2402.58+/-114.15$ & $4025.86+/-29.78$ & $6521.18+/-132.46$ & $9232.50+/-253.62$ \\
\hline $\begin{array}{c}\text { Feed B } \\
\text { Ratios 5 \& 11 }\end{array}$ & $2583.46+/-169.31$ & $4126.94+/-59.88$ & $7538.38+/-113.54$ & $6395.00+/-212.13$
\end{tabular}

The initial hydroalcoholic extracts, or feeds, presented a total phenolic content (TPC) in line with the reported concentration to be optimum for CGAs separation procedures, ie: $200 \mathrm{mg} \mathrm{GAE} / \mathrm{L}$ (Spigno et al., 2010; 2014). The total phenols content and the polyphenolic composition of both feeds is practically the same ; consisting mainly of caffeoylquinic acids - above $85 \%$ of their total composition - and a small proportion of flavones which is in agreement with the literature; more details on the identification and composition given below in 'polyphenol profile characterisation' section (3.5). Only a significant difference was found in antioxidant activity 
This variation may be due to the heterogeneous particle size of the artichoke residue which can result in variation in extracted phenols.

The total phenols content of the extract was comparable to others reported for artichoke. For example, Zuorro et al. (2014) reported a TPC: 2414 +/- mg GAE/100 g in outer bracts and stems using a 50:50 aqueous:ethanol solution, extraction time 90 minutes and included a blanching step. Curadi et al. (2005) used a methanolic solution to obtain a TPC: 480 - 2980 mg GAE/100 g in the edible parts of the plant. Speisky et al. (2004) studies on raw bracts and leaves of a Chilean variety of artichoke, which were reported to contain lower phenolic content than European ones resulted in TPC: $2320 \mathrm{mg}$ GAE/100g (dw) although using non food grade solvents, hexane/dichloromethane (1:1) followed by acetone/water/acetic acid (70:29.5:0.5). The antioxidant capacity measured here (Table 1 ) was lower that that reported by Speisky et al (2014), AOC: $52570 \mu \mathrm{mol} T E / 100 \mathrm{~g}(\mathrm{dw})$, using the same method and also lower than those reported for other plant extracts such as grape marc, 193-485 $\mu \mathrm{Mol}$ TE/g extract from grape marc by acidified methanol (Rockenback et al 2011); extract from white grape $284 \mu \mathrm{Mol}$ TE/g (Sanchez-Alonso, Jimenez-Escrig, Saura-Calixto and Borderias, 2008).

\subsection{Recovery and Separation Factor for Total Polyphenols, Proteins and}

\section{Sugars}

All experiments were carried out in duplicate and showed good reproducibility with coefficient of variability $(\mathrm{CV}) \%$ ranging 0.37 and $12 \%$ at all ratios except at ratio 2 with $\mathrm{CTAB}$ were $\mathrm{CV} \%=$ $32 \%$. 
Figure 3 shows the recovery (RE\%) for total polyphenols in CGAs samples produced with Tween 20 and CTAB at the volumetric ratios studied.

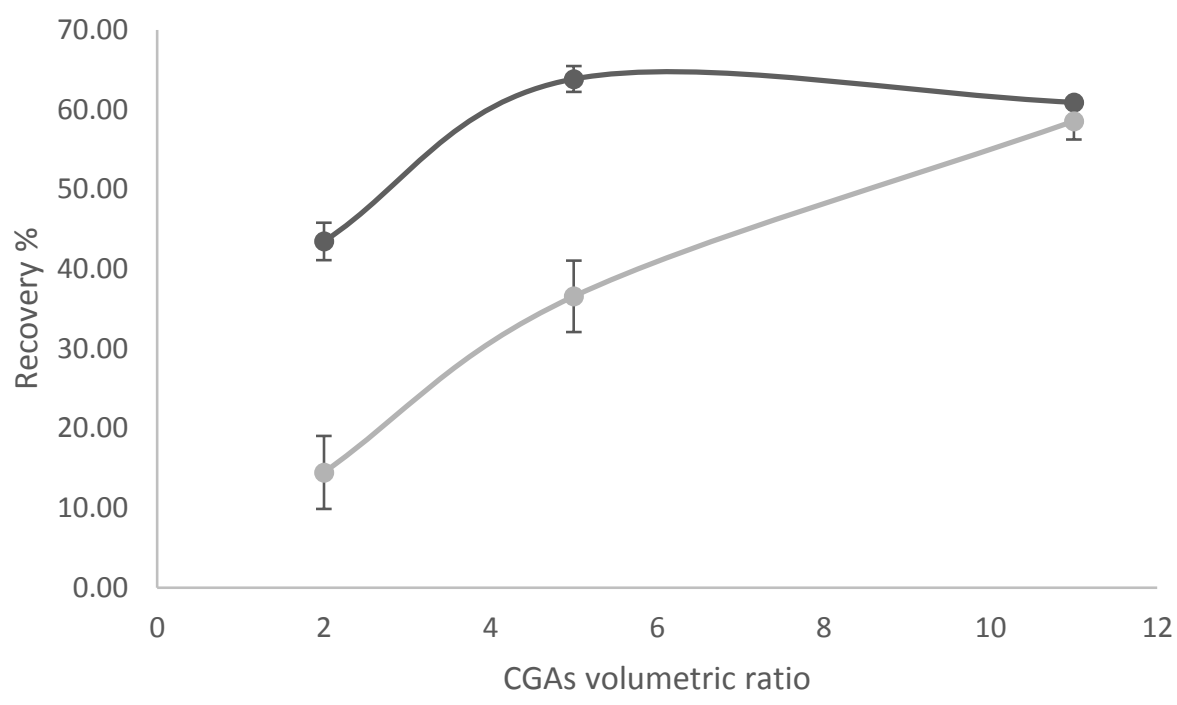

Figure 3. Recovery (RE\%) results for Tween ( $)$ ) and CTAB ( $\mathbf{0}$ ) at 2, 5, 11 volumetric ratios CGAs:Feed. Error bars indicate +/- SD.

Figure 3 shows that higher recoveries were obtained with Tween 20 than CTAB at volumetric ratios 2 and 5; three and two times more, respectively - 43\% RE\% with Tween 20 in contrast to $14 \%$ with $\mathrm{CTAB}$ at ratio $2,63.85 \%$ and $36.57 \%$ at ratio 5 -, indicating the separation is mainly driven by hydrophobic forces. This would be in agreement with Spigno et al. (2011), who observed hydrophobic forces to be the main ones driving the separation of phenolic compounds on an ethanolic grape marc extract as well as with Dermiki et al. (2009), who observed a higher recovery of astaxanthin with non-ionic surfactant Tween 60 than with cationic ones in an ethanolic solution. The highest result in terms of recovery of polyphenols was achieved at ratio 5 with Tween 20, which could open the possibility to use an innocuous non-ionic surfactant at these midrange volumetric ratios. However, it is worth noting that the volumes of the collected CGA phases were much higher - two or three times more - for Tween 20 than for CTAB, (Table 2) hence recovered polyphenols were more diluted. 
Table 2. Volumes ( $\mathrm{mL}$ ) collected for liquid (LP) and CGAs phases at ratios 2, 5, 11 generated with Tween 20 and CTAB (+/-Standard Deviation).

\begin{tabular}{cccc} 
& \multicolumn{3}{c}{ Volumes retrieved $(\mathrm{mL})$} \\
& Ratio 2 & Ratio 5 & Ratio 11 \\
LP Tween 20 & $246.80+/-0.141$ & $142.60+/-4.101$ & $127.65+/-2.616$ \\
CGAs Tween 20 & $179.65+/-27.64$ & $224.95+/-10.25$ & $197.20+/-2.687$ \\
LP CTAB & $381.05+/-7.707$ & $292.70+/-16.40$ & $219.55+/-0.354$ \\
CGAs CTAB & $81.85+/-1.626$ & $68.85+/-8.415$ & $116.45+/-16.05$
\end{tabular}

On the other hand, this great difference in recovery between the two surfactants was not observed at ratio 11; 60.91\% with CGAs from Tween 20 and 58.56\% with CGAs from CTAB, which is consistent with the similar volumes of CGA phases recovered for both surfactants. These very similar results in recovery of polyphenols obtained with Tween 20 and CTAB, suggests that at this ratio, both hydrophobic and electrostatic forces participate practically at the same level in the separation of polyphenols from the feed, which is in accordance with previous studies on grape marc extracts (Spigno et al., 2011; Spigno et al., 2015). However, it is worth noting the recovery achieved at this ratio with CGAs generated from Tween 20 was slightly lower to that of ratio 5 , suggesting a plateau was reached at midrange volumetric ratios. On the other hand, recovery of polyphenols with CGAs from CTAB increased with the volumetric ratio, achieving the highest values at ratio 11 , which is in agreement with works by Spigno et al. $(2011 ; 2014)$. Further research should be undertaken to establish the efficiency of higher volumetric ratios.

Electrostatic forces have been reported to be the main ones driving the separation of phenolic compounds using CGAs generated from a cationic surfactant as CTAB (Spigno et al., 2005; Fuda et al., 2005; Spigno and Jauregi, 2005). Additionally, Dermiki et al.(2009), reported electrostatic interactions to be the main forces driving the separation of astaxanthin from an aqueous solution, but hydrophobic ones when ethanol is present. This supports that CGAs generated 
from CTAB are more susceptible to the ethanol presence than those from Tween 20 , as it hinders electrostatic interactions (Dermiki et al., 2009; Spigno et al., 2011; Spigno et al., 2014). It also explains why higher results in terms of recovery are obtained at high volumetric ratios, where CGAs are more stable due to appropriate turbulence contact (Jauregi and Dermiki, 2010); additionally, at reduced volume of initial feed (increase volume ratio) meant in turn lower volumes of ethanol in the solution and hence, improved electrostatic interactions between CGAs and polyphenols.

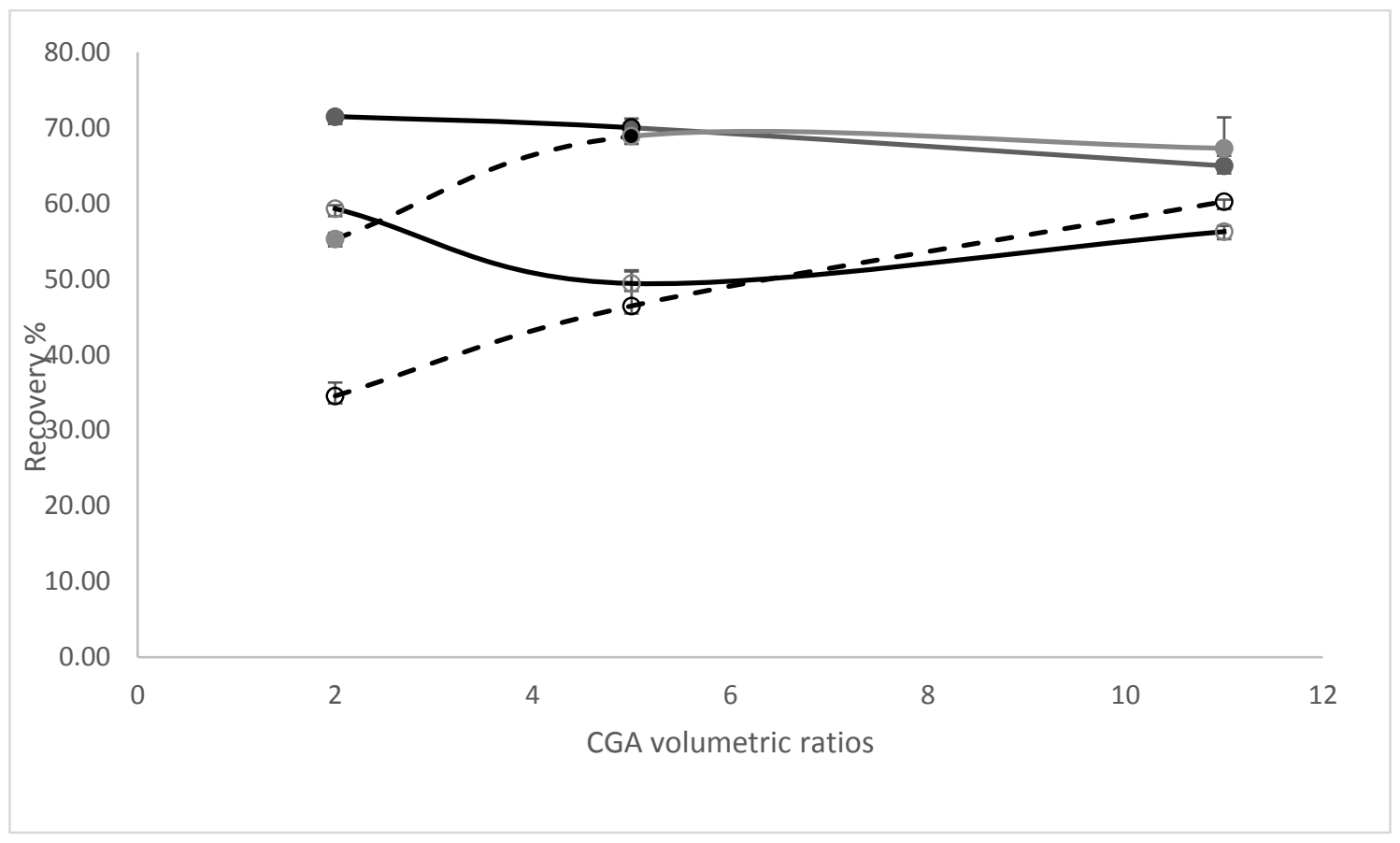

Figure 4. Recovery (\%) results of total protein (continuous line) and total sugar (dashed line) for Tween (black symbol) and CTAB (hollow symbol) CGAs phases at 2, 5, 11 volumetric ratios CGAs:Feed. Error bars indicate +/- SD.

Regarding the recovery (RE\%) of total proteins and total sugars, shown above in Figure 4, we again observe a higher RE\% for both molecules with CGAs generated from Tween 20 -always considering the much higher volume recovered of CGAs from the non-ionic surfactant - than CGAs from CTAB. The recovery of sugars showed a very similar pattern to that of polyphenols with the two studied surfactants, suggesting a very similar affinity for both compounds by CGAs. This can be also explained by complexation mechanisms between sugars and polyphenols 
resulting in their effective separation into the aphron phase, which could also contribute to the stability of polyphenols and therefore maintain antioxidant activity in the extract (Loncaric et al., 2014). It is also well known that polyphenols have high binding affinity for proteins; chlorogenic acid in particular, has been reported to show high binding affinity for sunflower proteins (Wildermuth et al., 2016). However different patterns in the recovery of proteins and polyphenols were observed in this study. Proteins were recovered mainly by hydrophobic forces, showing a similar efficiency of CGAs fractions generated from Tween 20 at all the ratios studied. Protein competition by protein-protein interactions could have led to decrease selectivity in the separation and therefore the irregular recoveries observed at different ratios with CGAs from CTAB. It could also explain the low recoveries of polyphenols in contrast with the particularly high recoveries of proteins observed at ratio 2 with the cationic surfactant .

Table 3. Separation Ratios (SR) (+/- SD) for Total Phenols, Total Proteins and Total Sugars at 2, 5, 11 (CGAs: Feed) volumetric ratios for CGAs generated from Tween 20 and CTAB (+/- Standard Deviation).

\begin{tabular}{|c|c|c|c|c|}
\hline $\begin{array}{c}\text { Volumetric } \\
\text { Ratios }\end{array}$ & CGAs & $\begin{array}{l}\text { SR Total } \\
\text { Phenols }\end{array}$ & $\begin{array}{l}\text { SR Total } \\
\text { Proteins }\end{array}$ & $\begin{array}{l}\text { SR Total } \\
\text { Sugars }\end{array}$ \\
\hline \multirow{2}{*}{2} & Tween 20 & $1.04+/-0.001$ & $1.03+/-0.009$ & $1.08+/-0.018$ \\
\hline & CTAB & $1.26+/-0.022$ & $1.25+/-0.010$ & $1.27+/-0.027$ \\
\hline \multirow{2}{*}{5} & Tween 20 & $1.11+/-0.002$ & $1.07+/-0.004$ & $1.08+/-0.018$ \\
\hline & CTAB & $2.18+/-0.050$ & $1.93+/-0.041$ & $1.81+/-0.020$ \\
\hline & Tween 20 & $1.18+/-0.009$ & $1.11+/-0.006$ & $1.12+/-0.0$ \\
\hline & CTAB & $2.634+/-0.114$ & $1.61+/-0.085$ & $2.2+/-0.052$ \\
\hline
\end{tabular}

Table 3 shows the Separation Ratio (SR) of total phenols, proteins and sugars. Very similar results for all compounds were obtained with Tween 20 at all volumetric ratios, indicating a similar concentration of the compounds both in the CGAs and liquid fractions, and therefore, low efficiency of the surfactant in concentrating the compounds in the CGAs fractions. However, 
higher results were obtained using CTAB than Tween 20 at all the volumetric ratios and for all the molecules. This indicates that CGAs generated from CTAB are much more efficient at interacting and extracting polyphenols than their liquid counterparts at all volumetric ratios studied, this being more obvious as the CGAs volumetric ratio increases. At ratios 11 and 5, CGAs phases are 2.6 and 2.2 times richer in polyphenols respectively than their liquid counterpart phases when using CTAB than Tween 20 (Table 3). Moreover the CGA generated by CTAB led to a more selective separation in terms of proteins and sugars than Tween; for instance, with CTAB at ratio 11 the SR of polyphenols is 1.6 times higher that of proteins and 1.3 higher that of sugars whilst for Tween the SR of polyphenols is the same as that of proteins and sugars (Table 3) so, no selectivity. This increased selectivity can also be explained by a more efficient drainage of the CGA phase with CTAB than with Tween (Table 2) which results in the removal of those molecules that interact less with the CTAB in the CGA.

Overall these findings are in agreement with those by Spigno et al (2015) as generally they found an improved recovery and separation at conditions that promoted electrostatic interactions between the polyphenols and the surfactant, ie: cationic surfactant and $\mathrm{pH}>2$. However, Spigno et al. (2015) reported that SR with Tween 20 were higher than those with CTAB at volumetric ratios $>10$. This discrepancy could be explained by the differences in polyphenols composition as the grape extract contains more complex and hydrophobic polyphenols such as anthocyanins which separate preferentially into the CGA phases generated from non-ionic surfactants (MohdMaidin et al., 2017). On the other hand, the main polyphenols in artichoke extract are caffeic acids with acidic pka's (Gallic acid: 4.41, Caffeic acid: 4.62, Serjeant and Dempsey, 1979) thus, at the $\mathrm{pH}$ of these experiments (5.8 - 6.1 in initial feed), they will be mainly ionised and hence negatively charged, favouring electrostatic interactions with the cationic surfactant.

\subsection{Antioxidant Activity}




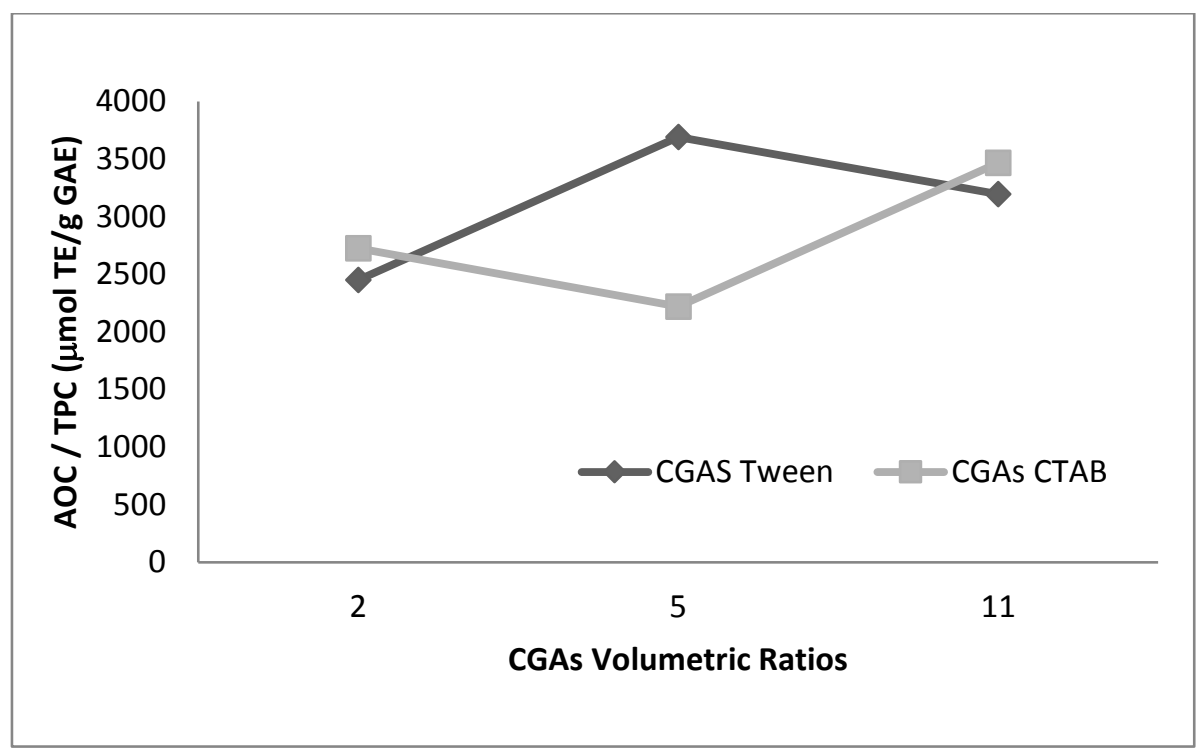

Figure 5. AOC/TPC results for Tween and CTAB CGAs phases at 2, 5, 11 volumetric ratios CGAs:Feed. Ratios calculated from the average values of AOC and TPC.

Figure 5 shows the ratio AOC/TPC for CGAs phases generated from Tween 20 and CTAB, relating antioxidant capacity displayed in a sample to its phenolic content. All CGAs phases presented higher AOC than their liquid counterparts both for Tween 20 and CTAB but lower than the initial extract. This is in contrast to previous findings from Spigno et al. (2015), who reported liquid phases to have greater $A O C$ than their counterpart CGAs phases and, in some cases, than the initial feed. We observe for Tween 20 an increase of the AOC from ratio 2 to ratio 5, and then a decrease towards ratio 11 , with a similar trend for the \%RE of polyphenols. The inverse pattern is observed for $C T A B$, where the $A O C$ decreases from ratio 2 to 5 and then increases at ratio 11 . This pattern is in accordance with that observed in RE\% for polyphenols, except at ratio 2 CTAB, where high AOC is observed considering the low recovery of polyphenols achieved at this ratio. This could be explained by a selective separation of non-polyphenolic compounds with antioxidant activity present in the extract, such as protein (60\% recovered at this ratio, Fig 4 ) and/or the fructan inulin (Stoyanova et al., 2010, Peshev et al., 2013). Highest results in terms of AOC/TPC were achieved at ratio 11 as for recovery with CGAs generated from both surfactants. Furthermore, when considering the AOC/TPC of CGAs samples against AOC/TPC of 
initial feed, which represents the enrichment of antioxidant capacity (Table 4) we observe a decrease in enrichment for Tween 20 and CTAB at ratio 2, showing the inefficiency of this ratio. However, CGAs generated from Tween 20 at ratio 5 showed an enrichment increase to 1.5, whereas at ratio 11 the enrichment was lower, 1.3. At this ratio the highest enrichment was obtained for CTAB (1.4) proving again the most efficient ratio, now in terms of antioxidant activity gain.

In summary, increase in volumetric ratio led to an increase in recovery of polyphenols and enrichment of antioxidant activity (AOC/TPC) CGAs / (AOC/TPC) Feed) for both surfactants. However, interestingly, for Tween 20 further increases above ratio 5 did not lead to an increase in recovery and/or enrichment in antioxidant activity. Conversely, maximum recovery and enrichment of antioxidant activity for CTAB were obtained at the highest ratio. This implies different mechanisms of the separation with the cationic and the non-ionic surfactants. In the case of the cationic surfactant, polyphenols separation into the CGA was mainly driven by their electrostatic interactions with the surfactant, thus an increase in the volumetric ratio led to an increase in recovery. On the other hand the separation with Tween was mainly driven by hydrophobic interactions with the surfactant in the CGA phase; but the surfactant will be also forming micelles and it can be assumed that in a bigger proportion than in the CTAB generated CGAs, given the much higher concentration used for Tween 20 (100 x CMC) than for CTAB ( about its $(M C)$. 
Table 4. Enrichment in antioxidant capacity from initial hydroalcoholic extracts for 2, 5, 11 (CGAs: Feed) volumetric ratios for CGAs generated from Tween 20 and CTAB (+/- Standard Deviation).

\begin{tabular}{cccc} 
& \multicolumn{3}{c}{$($ AOC/TPC) CGAs / (AOC/TPC) Feed } \\
& Ratio 2 & Ratio 5 & Ratio 11 \\
Tween 20 & $0.64+/-0.034$ & $1.49+/-0.015$ & $1.29+/-0.046$ \\
CTAB & $0.71+/-0.116$ & $0.90+/-0.055$ & $1.40+/-0.091$
\end{tabular}

\subsection{Polyphenolic Profile Characterization}

The polyphenolic profile of ethanolic extract as well as CGAs and liquid phases samples were characterised by HPLC techniques and further analyzed with LC-MS techniques for accuracy in identification and to gain further knowledge of the molecular composition of the compounds.

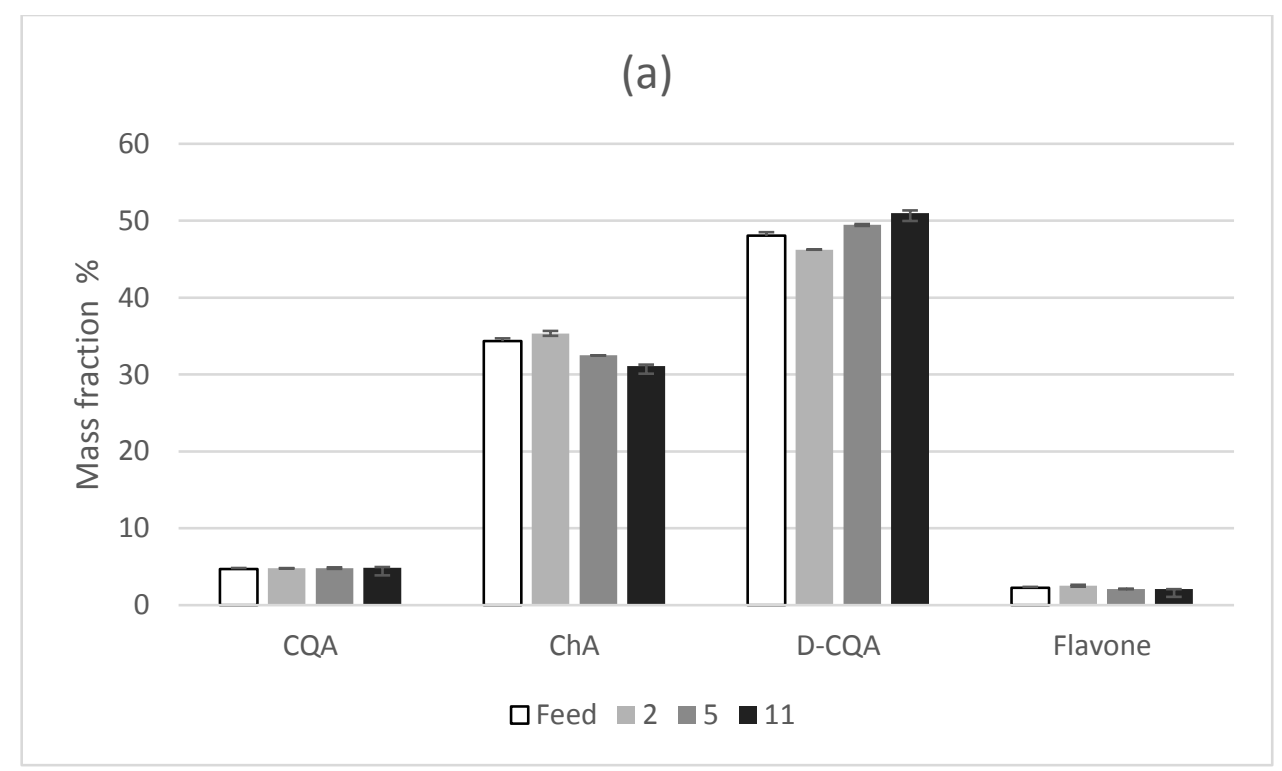


(b)

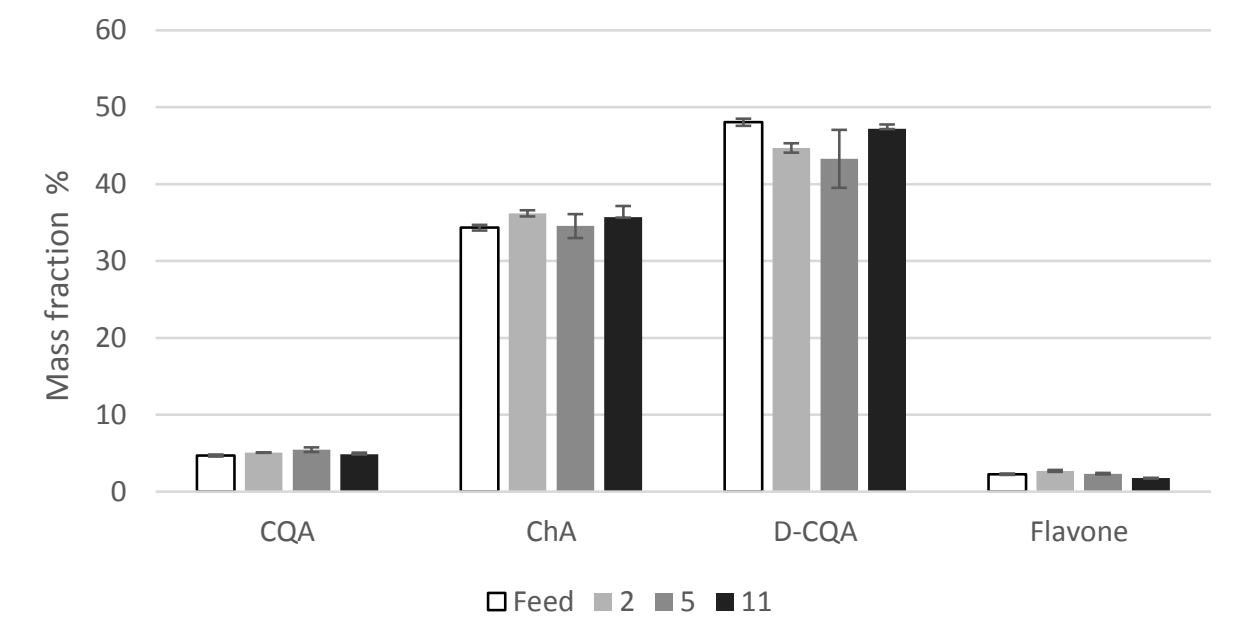

Figure 6 a, b. Mass fraction (\%) of main polyphenols in feed and (a) CGAs fractions from Tween 20, (b) CGAs fractions from CTAB at volumetric ratios 2, 5 and 11. CQA: (Mono)Caffeoylquinic acid, ChA: Chlorogenic acid; D-CQA: Di- caffeoylquinic acid. The values shown here are averages of samples obtained from the separation experiments carried out in duplicate except for the feed which corresponds to four replicas (duplicates of feeds A and B).

Figure $\mathbf{6} \mathbf{a}$ and $\mathbf{b}$ shows the phenolic content of initial extract and CGAs samples in terms of percentage mass fractions. The phenolic profile of both feed and CGAs samples were mainly composed of mono and dicaffeoylquinic acids, comprising more than $85 \%$ of all the total phenols present in the sample, which agrees with the literature (Wang et al., 2003; Pandino et al., 2010; Abu-Reidah et al., 2013; Ruiz-Cano et al., 2014). The most abundant compound (about 45-50\%) corresponds to a dicaffeoylquinic acid which has the same molecular weight as cynarin (1,3-diO-caffeoylquinic acid), $516 \mathrm{Da}$, however, the cynarin standard eluted at a different retention time. Possibly it could be an isomer of cynarin such as 1,5-di-O-caffeoylquinic acid or 3, 5-di-Ocaffeoylquinic acid based on previous studies (Pandino et al., 2010; Garbetta et al., 2014; 
Lombardo et al., 2010). These isomers could be more stable forms since cynarin has been reported to be unstable and therefore difficult to analyse (Da Costa et al., 2009). It could also be explained by the naturally low content of cynarin in South American varieties of artichoke, as the case of the study, as in agreement with Noldin et al. (2003). The second most abundant compound representing around $30 \%$ of the total was identified as chlorogenic acid (5-Ocaffeoylquinic acid) as confirmed by both comparison with retention times of the standard and MW. This is in line with results from previous studies, always considering the differences between varieties of the vegetable (Romani et al., 2006; Pandino et al., 2012; Abu-Reidah et al., 2013). The third most abundant phenol (about $5 \%$ ) is a caffeoylquinic acid with same MW as chlorogenic acid,353 Da, which could correspond to an isomer, very likely 3-O-caffeoylquinic acid based on previous studies (Schutz et al., 2006; Sánchez-Rabaneda et al., 2003; Ruiz-Cano et al., 2014). Lowest polyphenolic fraction (about 2\%) corresponds to a flavone, with the same molecular weight as apigenin (4', 5, 7-trihydroxyflavone), 269 Da, very likely a glycoside form of apigenin, as could be apigenin-7-glucuronide, which has been reported to be one of the most representative flavonoids (Ceccarelli et al., 2010; Garbetta et al., 2014; Lombardo et al., 2010; Pandino et al., 2012).

In most of the cases there was no significant enrichment of any particular polyphenol from feed to CGAs samples, which had a very similar composition at the different ratios. This observation also applied amongst the CGAs and liquid phase samples obtained. In the case of CTAB there was no significant change in composition at different ratios and in relation to the feed (Fig $\mathbf{6} \mathbf{b}$ ). There was only a statistically significant $(p<0.05)$ increase in caffeoylquinic acid $(C Q A)$ at ratio 5 in relation to the feed. The changes in flavone composition were small but statistically significant, with an increase in composition at lower ratios. The most significant changes were detected for Tween (Fig 6a) where at increased ratio the composition of chlorogenic acid decreased in relation to the feed whilst the composition of dicaffeoylquinic acid increased. Moreover it is worth mentioning that the dicaffeoylquinic acid fraction in CGAs generated with 
Tween 20 at ratio 5 (49.4\%) was higher than that from CGAs obtained with CTAB (43.3\%). Dicaffeoylquinic acids are reported to display great AOC, especially when their hydroxyl groups are in ortho or para position in relation to the carboxyl group functional group, and the when double bonds between the carbon atoms are present (Wang et al, 2003; Balasundram et al., 2006). Thus, this high content of the dicaffeoylquinic acid in the CGAs phase from Tween 20 at ratio 5 could have contributed to the highest antioxidant enrichment (1.49) obtained at these conditions (Table 4) and conversely, its deficiency in CTAB to the low antioxidant enrichment (0.90).

Overall the CGA separation led to extracts enriched in antioxidant activity, with a similar polyphenol composition to the raw extract and with a lower content of proteins and sugars.

So in principle these extracts could be formulated into food products such as soups or sauces (emulsions) where the presence of the surfactant may be an advantage although in this case, a food grade surfactant such as Tween 20 will need to be used. Other nonfood applications such as cosmetic products and sunscreens (MohdMaidin, 2017; Galanakis 2018) can also be very interesting applications particularly, for the CTAB extracts where the toxicity of the surfactant may not be an issue.

\section{CONCLUSION}

This study shows that CGA can be used successfully in order to recover polyphenols with antioxidant activity from an aqueous/ethanolic solution of artichoke (Cynara scolymus) agroindustrial discards (outer leaves and bracts). The separation is driven by both hydrophobic and electrostatic interactions. Highest recovery was obtained with the nonionic Tween 20 at midrange volumetric ratios (ratio 5) whereas the cationic CTAB proved more efficient at the highest ratio studied here (ratio 11). . Low volumetric ratios did not show suitability for the recovery of polyphenols neither with Tween 20 nor with CTAB. Antioxidant capacity followed the same trend 
as the recovery of polyphenols and highest enrichment in antioxidant activity was obtained also at those conditions that led to maximum recovery. Proteins and sugars separated together with polyphenols, most probably due to their complexation. CGAs fractions generated from CTAB were two times more concentrated in polyphenols than their liquid counterparts, at all the ratios studied. This was not observed with Tween 20, where CGAs and liquid phases were similarly concentrated. Also, the selectivity of the CTAB in relation to proteins and sugars was superior to that of Tween 20; partly possibly due to the more efficient drainage. These differences implied a different mechanism of interaction between the polyphenols and CGAs generated from the non-ionic and the cationic surfactants. The interactions between the negatively charged polyphenols and the positively charged cationic surfactant drove the separation, whereas with Tween 20 hydrophobic interactions were predominant, and at the studied concentrations the separation of polyphenols within the micelles might also compete with the CGA separation. Polyphenolic profile of feed and CGAs fractions comprised mainly mono and dicaffeoylquinic acids and a small proportion of flavones. In most of the cases no enrichment of any particular polyphenol compound was observed from the initial extract to CGAs samples generated with Tween 20 and CTAB. However, at ratio 5 and with Tween, CGAs were enriched in dicaffeoylquinic acid.

Future research should focus on studying further the activities and stability of these surfactant rich fractions in order to assess if the surfactant could offer any advantage to the formulation of these polyphenols for their application in food, cosmetics and/or medicinal products.

\section{Conflicts of interest}

The authors declare no conflict of interest. The present article is part of the doctoral thesis of Ms Diana Noriega.

\section{Acknowledgments}


The authors would like to thank the technical help and support provided by the Department of Food and Nutritional Sciences at the University of Reading. We would also like to extend our gratitude to CONICYT R15F10006 project, and Centro Regional de Estudios en Alimentos Saludables (CREAS) CONICYT-GORE R17A10001 for funding and make this project possible.

\section{REFERENCES}

1. Jiménez-Escrig A, Dragstead L, Daneshvar B, Pulido R, Saura-Calixto F. In vitro Antioxidant Activity of Edible Artichoke (Cynara scolymus) and Effect on Biomarkers of Antioxidants in Rats. Journal of Agriculture and Food Chemistry 51: 5540 - 5545 (2003). DOI: 10.1021/jf030047e

2. Ceccarelli N, Curadi M, Picciarelli P, Martelloni L, Sbrana C, Giovanetti M. Globe artichoke as a functional food. Mediterranean Journal of Nutrition and Metabolism 3: 197 - 201 (2010). DOI: $10.1007 /$ s12349-010-0021-z

3. Ruiz-Cano D, Pérez-Llamas F, Frutos M J, Arnao M, Espinosa C, López-Jiménez J A, Castillo J, Zamora S. Chemical and functional properties of the different by-products of artichoke (Cynara scolymus L.) from industrial canning processing. Food Chemistry 160: 134-140 (2014). DOI: 10.1016/j.foodchem.2014.03.091

4. Lattanzio V, Kroon P, Linsalata V, Cardinali A. Globe artichoke: A functional food and source of nutraceutical ingredients. Journal of Functional Foods 1: 131-144 (2013). DOI: 10.1016/j.jff.2009.01.002

5. Da Costa R S, Ferreira-Ozela E, Ramos W L, Lindolfo N, Carréra Silva J R. Caracterização física, química e físico-química do extrato seco por nebulização (spray-drying) de Cynara scolymus L. (Asteraceae) Revista Brasileira de Farmácia 90 (3): 169-174 (2009) 
6. Bekheet SA. In vitro biomass production of liver-protective compounds from Globe artichoke (Cynara scolymus L) and Milk thistle (Sylibum marianum) plants. Emirates Journal of Food and Agriculture 23(5): 473-481 (2011). DOI: 5641a187108ae295f644fb33a

7. Shukla S and Gupta S, Apigenin: a promising molecule for cancer. Pharmaceutical Research 27: $962-978$ (2010). DOI: 10.1007/s11095-010-0089-7

8. Pereira C, Calhelha R, Barros L, Ferreira I. Antioxidant properties, anti-hepatocellular carcinoma activity and hepatotoxicity of artichoke, milk thistle and borututu. Industrial Crops and Products 49: 61- 65 (2013). DOI: 10.1016/j.indcrop.2013.04.032

9. Marakis G, Walker A F, Middleton R W, Booth J C L, Wright J, Pike D J: Artichoke leaf extract reduces mild dyspepsia in an open study. Phytomedicine 9(8): 694-699 (2002). DOI: $10.1078 / 094471102321621287$

10. Zhu X, Zhang H, Lo R. Phenolic Compounds from the Leaf Extract of Artichoke (Cynara scolymus L.) and Their Antimicrobial Activities. Journal of Agriculture and Food Chemistry 52: $7272-7278$ (2004). DOI: 10.1021/jf0490192ISSN 2225-093X

11. Gaafar A and Salama A. Phenolic Compounds from Artichoke (Cynara scolymusL.) Byproducts and their Antimicrobial Activities. Food and Nutrition Sciences 3(12): 2053-2062 (2013). ISSN 2225-093X

12. Fratianni F, Pepe, R and Nazzaro F, Polyphenol Composition, Antioxidant, Antimicrobial and Quorum Quenching Activity of the "Carciofo di Montoro" (Cynara cardunculus var. scolymus) Global Artichoke of the Campania Region, Southern Italy. Food and Nutrition Sciences 5: 2053-2062 (2014). DOI: 10.4236/fns.2014.521217

13. Negro D, Montesano V, Grieco S, Crupi P, Sarli G, De Lisi A, Sonnante G. Polyphenol Compounds in Artichoke Plant Tissues and Varieties. Journal of Food Science 77 (2): 244 252 (2012). DOI: 10.1111/j.1750- 3841.2011.02531.x 
14. Pandino G, Lombardo S, Mauromicale G, Globe artichoke leaves and floral stems as a source of bioactive compounds. Industrial Crops and Products 44: $44-49$ (2013). DOI: 10.1016/j.indcrop.2012.10.022

15. Llorach, R., Espín, J. C., Tomás-Barberán, F. A., Ferreres, F. Artichoke (Cynara scolymus) Byproducts as a Potential Source of Health-Promoting Antioxidant Phenolics. Journal of Agriculture and Food Chemistry 50: 3458-3464 (2002). DOI: 10.1021/jf0200570

16. Schutz K, Muks E, Carle R, Schieber A. Quantitative Determination of Phenolic Compounds in Artichoke-Based Dietary Supplements and Pharmaceuticals by High-Performance Liquid Chromatography. Journal of Agriculture and Food Chemistry 54: 8812-8817 (2006) DOI: $10.1021 / \mathrm{jf062009b}$

17. Garbetta A, Capotorto I, Cardinali A, D'Antuono I, Linsalata V, Pizzi F and Minervini F. Antioxidant activity induced by main polyphenols present in edible artichoke heads: influence of in vitro gastro-intestinal digestion. Journal of Functional Foods 10: 456-464 (2014). DOI: 10.1016/j.jff.2014.07.019

18. Galanakis, C. Emerging technologies for the production of nutraceuticals from agricultural by-products: a viewpoint of opportunities and challenges. Food and Bioproducts Processing 91: 575-579 (2013). DOI: 10.1016/j.fbp.2013.01.004

19. Wang M, Simon JE, Aviles IF, He K, Zheng Q and TadmorY Analysis of Antioxidative Phenolic Compounds in Artichoke (Cynara scolymus L.) Journal of Agriculture and Food Chemistry 51 : 601-608 (2003). DOI: 10.1021/jf020792b

20. Pandino G, Courts F, Lombardo S, Mauromicale G, Williamson G. Caffeoylquinic Acids and Flavonoids in the Immature Inflorescence of Globe Artichoke, Wild Cardoon, and Cultivated Cardoon. Journal of Agriculture and Food Chemistry 58: 1026-1031 (2010). DOI: $10.1021 / \mathrm{jf903311 \textrm {j }}$ 
21. Zuorro A, Maffei G, Lavecchia R. Effect of solvent type and extraction conditions on the recovery of phenolic compounds from artichoke waste. Chemical Engineering Transactions 39: 463-468 (2014). DOI: 10.3303/CET1439078

22. Soto $C$, Caballero E, Pérez E, Zúñiga ME. Effect of extraction conditions on total phenolic content and antioxidant capacity of pretreated wild Peumus boldus leaves from Chile. Food and Bioproducts Processing 92: 328-333 (2014). DOI: 10.1016/j.fbp.2013.06.002

23. Galanakis C. Trends in Food Science \& Technology 2012 26, 68-87 (2012). DOI: 10.1016/j.tifs.2012.03.003

24. MohdMaidin N, Michael N, Oruna-Concha MJ, Jauregi P. Polyphenols extracted from red grape pomace by a surfactant based method show enhanced collagenase and elastase inhibitory activity. Journal of Chemical Technology and Biotechnology (Accepted September 2017). DOI: $10.1002 / j c t b .5459$

25. Sebba F. Foams and biliquid foams - aphrons. Wiley VII: 236 (1987). DOI: 10.1002/adma.19890010312

26. Jauregi P and Varley J. Colloidal gas aphrons: potential applications in biotechnology. Trends in Biotechnology 17(10): 389-395 (1999). DOI: 10.1016/S0167-7799(99)01363-3

27. Jauregi $\mathrm{P}$ and Dermiki M. Separation of value-added bioproducts by colloidal gas aphrons (CGA) flotation and applications in the recovery of value-added food products. Woodhead Publishing Limited, Cambridge In Separation, Extraction and Concentration Processes in Food, Beverage and Nutraceutical Industries: 284-313 (2010). ISBN : 9781845696450

28. Mansur EH, Wang $\mathrm{Y}$ and Dai $\mathrm{Y}$. Removal of suspensions of fine particles from water by colloidal gas aphrons (CGAs). Separation and Purification Technology 48(1): $71-77$ (2006). DOI: 10.1016/j.seppur.2005.07.022

29. Spigno G, Amendola D, Dahmoune F, Jauregi P. Colloidal gas aphrons based separation process for the purification and fractionation of natural phenolic extracts. Food and Bioproducts Processing 94: 434-442 (2015). DOI: 10.1016/j.fbp.2014.06.002 
30. Dermiki M, Gordon MH and Jáuregui P. Recovery of astaxanthin using colloidal gas aphrons (CGA): A mechanistic study. Separation and Purification Technology 65: 54-64 (2009). DOI: 10.1016/j.seppur.2007.12.023

31. Spigno, G., Dermiki, M., Pastori, C., Jauregi, P. Recovery of gallic acid with colloidal gas aphrons generated from a cationic surfactant. Separation and Purification Technology; 71(1): 56-62 (2010) DOI: 10.1016/j.seppur.2009.11.002

32. Spigno G, Amendola D, Dermiki M, Jauregi P. Recovery of phenolic compounds from a grape marc extract with colloidal gas aphrons. In ICEF International Congress on Engineering and Food: 22-26 (2011). ISBN: 978-960-89789-3-5

33. Huang Y, Wang Y, Dai Y. Separation of Organic Dyes from Water using Colloidal Gas Aphrons. Tsinghua Science and Technology 7(1): 46-51 (2002). ISSN: 1007-0214

34. Mukhopadhyay S, Mukherjee S, Hashim M, Hashim MA, Gupta BS. Application of colloidal gas aphron suspensions produced from Sapindus mukorossi for arsenic removal from $\begin{array}{llllll}\text { contaminated soil. Chemosphere 119: 355-362 (2015). DOI: } & \end{array}$ 10.1016/j.chemosphere.2014.06.087

35. Molaei A, Waters KE. Aphron applications - A review of recent and current research. Advances in Colloid and Interface Science 216: 36-54 (2015). DOI: 10.1016/j.cis.2014.12.001

36. Noble M, Varley J. Colloidal gas aphrons generated from the anionic surfactant AOT for the separation of proteins from aqueous solution. Chemical Technology and Biotechnology 74(3): $\quad 231-237 \quad$ (1999). $\quad$ DOI: $10.1002 /(S I C I) 1097-4660(199903) 74: 3<231:: A I D-$ JCTB20>3.0.CO;2-9

37. Hashim MA, Kumar SV, Gupta BS. Particle-bubble attachment in yeast flotation by colloidal gas aphrons. Bioprocess and Biosystems Engineering 22: 333-336 (2000). DOI: $10.1007 / \mathrm{s} 004490050740$ 
38. Fuda E, Jauregi P, Pyle DL. Recovery of Lactoferrin and Lactoperoxidase from Sweet Whey Using Colloidal Gas Aphrons (CGAs) Generated from an Anionic Surfactant, AOT. Biotechnology Progress 20(2): 514-525 (2004). DOI: 10.1021/bp034198d

39. Fuda E, Bhatia D, Pyle DL, Jauregi P. Selective separation of $\beta$-lactoglobulin from sweet whey using CGAs generated from the cationic surfactant CTAB. Biotechnology and Bioengineering 90(5): 532-542 (2005). DOI: 10.1002/bit.20412

40. Alves RW, Ulson de Souza AA, Ulson de Souza SM, Jauregi P. Recovery of norbixin from a raw extraction solution of annatto pigments using colloidal gas aphrons (CGAs). Separation and Purification Technology 48: 208-213 (2006). DOI: 10.1016/j.seppur.2005.07.014

41. Spigno G and Jauregi P. Recovery of Gallic Acid with Colloidal Gas Aphrons (CGA). International Journal of Food Engineering 1(4): (2005). DOI: 10.2202/1556-3758.1038

42. Lin Q, Wang J, Quin, Bergenståhl B. Influence of amphilic structures on the stability of polyphenols with different hydrophobicity. Science in China Series B 50(1): 121-126 (2007). DOI: $10.1007 / \mathrm{s} 11426-007-0009-9$

43. Yutani R, Morita S, Traoke R, Kitiwaga S. Distribution of Polyphenols and a Surfactant Component in Skin during Aerosol OT Microemulsion-Enhanced Intradermal Delivery. Chemical and Pharmaceutical Bulletin 60(8): 989-994 (2012). DOI: 10.1248/cpb.c12-00230

44. Amiri MC and Sadeghialiabadi H. Evaluating the stability of colloidal gas aphrons in the presence of montmorillonite nanoparticles. Colloids and Surfaces A: Physicochemical and Engineering Aspects 457 (5): 212-219 (2015). DOI: 10.1016/j.colsurfa.2014.05.076

45. DuBois M, Gilles KA, Hamilton JK, Rebers PA, Smith F. Colorimetric Method for Determination of Sugars and Related Substances. Analytical Chemistry 28 (3): 350-356 (1956). DOI: 10.1021/ac60111a017

46. Soto C, Caballero E, Pérez E, Zúñiga ME. Effect of extraction conditions on total phenolic content and and antioxidant capacity on pretreated wild Peumus boldus leaves from Chile. Food and Bioproducts Processing 92: 328-333 (2014). DOI: 10.1016/j.fbp.2013.06.002 
47. Pellegrini N, Proteggente A, Pannala A, Yang M, Rice-Evans C. Antioxidant activity applying an improved ABTS radical cation decolorization assay. Free radical biology and medicine $\mathbf{2 6}$ (9): 1231-1237 (1999). DOI: 10.1016/S0891-5849(98)00315-3

48. Curadi M, Picciarelli P, Lorenzi R, Grainfenberg A. Antioxidant activity and phenolic compounds in the edible parts of early and late Italian artichoke (Cynara scolymus L.) varieties. Italian Journal of Food Science 17: 33-44(2005). DOI:

49. Speisky H., Base de datos de contenido y actividad antioxidante ORAC en frutas: Un sistema de sustentación de las exportaciones y de promoción de su consumo, Instituto de Nutrición y Tecnología de los Alimentos (2011)

50. Sanchez-Alonso I, Jimenez-Escrig A, Saura-Calixto F, Borderias AJ. Antioxidant protection of white grape pomace on restructured fish products during frozen storage. LWT - Food Science and Technology, 41(1): 42-50. (2008) . DOI: 10.1016/j.Iwt.2007.02.002

51. Rockenback II, Rodrigues E, Gonzaga, LV, Caliari, V, Genovese, MI, Gonaves AEDSS, Fett R. Phenolic compounds content and antioxidant activity in pomace from selected red grapes (Vitis vinifera L. and Vitis labrusca L.) widely produced in Brazil. Food Chemistry, 127(1): 174179 (2011). DOI: 10.1016/j.foodchem.2010.12.137

52. Loncaric A, Dugalic K, Mihaljevic I, Jakobek L, Pilizota V. Effects of Sugar Addition on Total Phenolic Content and Antioxidant Activity on Frozen and Freeze-Dried Apple Purée. Journal of Agricultural and Food Chemistry 62: 1674 - 1682 (2014). DOI: 10.1021/jf405003u

53. Wildermuth SR, Young EE, Were LM. Chlorogenic Acid Oxidation and its Reaction with Sunflower Proteins to Form Green-Coloured Complexes. Comprehensive Reviews in Food Science and Food Safety 15: 829 - 843 (2016). DOI: 10.1111/1541-4337.12213

54. Serjeant EP and Dempsey B. Ionisation Constants of Organic Acids in Aqueous Solution. International Union of Pure and Applied Chemistry (IUPAC). IUPAC Chemical Data Series No. 23 Pergamon Press, New York (1979) DOI: 10.1007/978-94-009-5883-8

55. Stoyanova S, Geuns J, Hideg E, Van Den Ende W. The food additives inulin and stevioside counteract oxidative stress. International Journal of Food Sciences and Nutrition 62(3): DOI: 207 - 214 (2010). DOI: 10.3109/09637486.2010.523416 
56. Peshev D, Vergauwen R, Moglia A, Hideg E, Van Den Ende W. Towards understanding vacuolar antioxidant mechanisms: a role for fructans? Journal Experimental Botany 64(4): 1025 - 1038 (2013). DOI: 10.1093/jxb/ers377

57. Abu-Reidah IM, Arráez-Román D, Segura-Carretero A, Fernández-Gutiérrez A. Extensive characterization $\mathrm{f}$ phenolic constituents from Globe Artichoke (Cynara scolymus L) by HPLCDAD-ESI-QTOF-MS. Food Chemistry 141(3): 2269 - 2277 (2013). DOI: 10.1016/j.foodchem.2013.04.066

58. Lombardo S, Pandino G, Muromicale G, Knödler M, Carle R, Schieber A. Influence of genotype, harvest time and plant part on polyphenolic composition of 2010 Globe Artichoke [Cynara carduluncus L var. scolymus (L.) Fiori]. Food Chemistry 119: 1175 - 1181 (2010). DOI: 10.1016/j.foodchem.2009.08.033

59. Noldin VF, Filho VC, Monache F, Benasi JC, Christmann IL, Pedrosa RC,Yunes RA. Composicao quimica e atividades biológicas das folhas de Cynara scolymus L. (Alcachofra) cultivada no Brasil. Quimica Nova 26(3): 331-334 (2003). DOI: 10.1590/\$0100-40422003000300008

60. Romani Pinelli Cantini Cimato Heimler. Characterization of Violetto di Toscana, a typical Italian variety of artichoke (Cynara scolymus L). Food Chemistry (95): 221 - 225 (2006). DOI: 10.1016/j.foodchem.2005.01.013

61. Sánchez-Rabaneda F, Jáuregui O, Lamuela-Raventos RM, Bastida J, Viladomata F and CodinaC, Identification of phenolic compounds in artichoke waste by high performance liquid chromatography-tandem mass spectrometry. Journal of Chromatography 1008: 57 72 (2003). DOI: 10.1016/S0021-9673(03)00964-6

62. Pandino Lombardo Williamson Mauromicale. Polyphenol Profile and Content in Wild and Cultivated Cynara Cardunculus L. Italian Journal of Agronomy 7:e35 (2012). DOI: 10.4081/ija.2012.e35 
63. Balasundram N, Sundram K, Samman S. Phenolic compounds in plants and agro-industrial by-products: Antioxidant activity, occurrence, and potential uses. Food Chemistry 99: 191 203 (2006). DOI: 10.1016/j.foodchem.2005.07.042

64. Galanakis, C. Phenols from olive mill wastewater and other natural antioxidants as UV filters in sunscreens, Environmental Technology \& Innovation, 2018, 9, 160168DOI:10.1016/j.eti.2017.12.002 